\title{
The role of JUN in the regulation of PRKCC-mediated STAR expression and steroidogenesis in mouse Leydig cells
}

\author{
Pulak R Manna and Douglas M Stocco \\ Department of Cell Biology and Biochemistry, Texas Tech University Health Sciences Center, Lubbock, Texas 79430, USA \\ (Correspondence should be addressed to D M Stocco; Email: doug.stocco@ ttuhsc.edu)
}

\begin{abstract}
Activator protein 1 (JUN) transcription factors (JUN and FOS) play critical roles in a wide variety of signaling processes including those in the protein kinase $\mathrm{C}$ (PRKCC) pathway, a pathway that is instrumental in the expression of the steroidogenic acute regulatory (STAR) protein. In the present study, we determined the functional involvement of one of the key JUN family members, JUN, in the regulation of PRKCC-dependent STAR expression and steroidogenesis. MA-10 mouse Leydig tumor cells treated with an activator of PRKCC, phorbol 12-myristate 13-acetate (PMA), demonstrated increases in the expression of the STAR and CYP11A1 proteins and progesterone synthesis, which coincided with the expression and phosphorylation of JUN (P-JUN). PMA was also capable of enhancing the cAMP analog, $(\mathrm{Bu})_{2} \mathrm{CAMP}$, which stimulated JUN, STAR, P-STAR and progesterone levels. The induction of Jun mRNA expression and steroid synthesis by PMA requires de novo protein synthesis. Chromatin immunoprecipitation studies revealed the association of P-JUN with the STAR proximal promoter and that PMA specifically enhanced in vivo P-JUN-DNA interaction. Electrophoretic mobility shift assays and reporter gene analyses demonstrated that JUN binds to the JUN motif ( $-81 /-75 \mathrm{bp}$ ) in the STAR promoter, and that JUN-DNA-binding activity was highly correlated with the induction of JUN by PRKCC signaling. Overexpression of JUN increased the PMA-mediated transcription of the Star gene, an event markedly decreased by TAM-67, a dominant negative mutant of JUN. Targeted silencing of endogenous JUN, by small interfering RNA, was correlated with the repression of basal- and PMA-mediated STAR expression and progesterone synthesis. These findings describe the mechanisms by which JUN influences PRKCC signaling and provide additional and novel insight into the regulation of the steroidogenic machinery in mouse Leydig cells.
\end{abstract}

Journal of Molecular Endocrinology (2008) 41, 329-341

\section{Introduction}

The biosynthesis of steroid hormones is initiated upon mobilization of cholesterol from cellular stores to the mitochondrial inner membrane that is the site of cytochrome $\mathrm{P} 450$ cholesterol side chain cleavage enzyme (CYP11A1) and is the rate-limiting and regulated step in steroidogenesis. The $37 / 30 \mathrm{kDa}$ steroidogenic acute regulatory (STAR) protein mediates this crucial step and has been demonstrated to be an acute regulator of steroidogenesis in steroidogenic tissues (Clark et al. 1994, Lin et al. 1995, Stocco \& Clark 1996, Christenson \& Strauss 2000, Manna \& Stocco 2005, Miller 2007). Transcriptional and/or translational inhibition of STAR expression has been shown to markedly decrease steroid biosynthesis, whereas $\sim 10$ $15 \%$ of steroid synthesis is mediated by STAR-independent mechanisms (Lin et al. 1995, Clark et al. 1997, Manna et al. 2001, Manna \& Stocco 2005). In the adrenals and gonads, while the cAMP/protein kinase A (PRKACA) pathway is the predominant signaling cascade involved in tropic hormone-stimulated STAR expression and steroid biosynthesis, PRKCC has also been demonstrated to play a role in these processes (Stocco \& Clark 1996, Jo et al. 2005, Manna \& Stocco 2005, Manna et al. 2007). By itself, the effect of PRKCC on steroid synthesis is considerably less than that of PRKACA signaling; however, PRKCC can potentiate gonadotropin and/or cAMP-mediated steroidogenic responsiveness, and by doing so, undoubtedly functions in gonadal/adrenal steroidogenic processes reviewed in Refs Manna \& Stocco (2005) and Stocco et al. (2005).

While the PRKCC signaling cascade has been demonstrated to be involved in influencing the steroidogenic response, there are conflicting reports in the literature that demonstrate either positive, negative, or no effects of PRKCC on steroidogenesis in different cell models reviewed in Ref. Stocco et al. (2005). We have demonstrated that activation of the PRKCC pathway dramatically increases STAR expression but only moderately elevates progesterone synthesis, and that the latter process is due to the inability of PRKCC to phosphorylate STAR (Jo et al. 2005, Stocco et al. 2005, Manna et al. $2006 a, b)$, a requirement indispensable for optimal steroid synthesis (Arakane et al. 1997, LeHoux et al. 2004). Notably, while PRKCC, by itself, had no effect on 
STAR phosphorylation, it greatly enhanced cAMPstimulated phosphorylation of STAR at Ser194 and concurrently steroid synthesis in mouse Leydig cells (Jo et al. 2005, Manna et al. 2006b, 2007). However, those studies did not provide information on the regulatory mechanisms by which PRKCC signaling is evolved in STAR expression and steroidogenesis.

Mapping of STAR promoter sequences in mouse demonstrated the importance of the first 150 nucleotides (highly conserved in other species) in the transcriptional regulation of the Star gene (Manna et al. 2002a, 2003b, Hiroi et al. 2004, Clem et al. 2005). Within this region, we have identified a motif $\left(5^{\prime}\right.$-TGACTGA- $\left.3^{\prime}\right)$ that recognizes both the cAMP response element (CRE) and JUN (JUN and FOS) family proteins (Manna et al. 2002a, 2004). JUN (JUN, JUNB, and JUND) and FOS (FOS, FOSB, FOSL1, and FOSL2) belong to the basic leucine zipper (bZIP) group of transcription factors that bind to DNA as dimers. In particular, they bind to the sequence TGA $(\mathrm{C} / \mathrm{G}) \mathrm{TCA}$, referred to as the tetradecanoylphorbol acetate response element (JUN/TRE), with distinct affinity and specificity, but exhibit varying degrees of transcriptional activity (O'Shea et al. 1992, Rutberg et al. 1997, Bakiri et al. 2002). The closely related CRE (TGACGTCA) is also a target for selective JUN/FOS dimers (Hai \& Curran 1991, Rutberg et al. 1999, Manna \& Stocco 2007). JUN and FOS are immediateearly response genes and are thought to function in coupling extracellular signals to phenotypic responses by influencing the expression of target genes. These factors are induced by a wide range of extracellular stimuli, including PRKCC and also by processes associated with mitogenesis, differentiation, and neuronal excitation (Abate et al. 1991, Karin et al. 1997, Li et al. 1997, Manna et al. 2002b, 2004). Furthermore, phosphorylation of JUN/FOS on Ser and Thr residues has been reported to be involved in the transcription of a number of genes (Abate $e t$ al. 1993, Chen et al. 2001, Manna et al. 2006b, Manna \& Stocco 2007). Utilizing MA-10 mouse Leydig tumor cells, a cell line possessing many characteristics of its normal counterparts, as an experimental model, the present findings provide for the first time evidence that JUN binds, both in vivo and in vitro, to the JUN motif in the STAR promoter where it is effective in regulating PRKCC-mediated STAR expression and steroidogenesis.

\section{Material and methods}

\section{Plasmids, transfections, and luciferase assays}

The $-151 /-1$ (JUN Wt) and $-151 /-1$ JUN mutant (JUN Mut) STAR promoters were constructed and subcloned into the pGL3 basic vector (Promega) that contains the firefly luciferase gene as a reporter (Manna et al. 2002a, 2004). The wild type JUN, dominant negative JUN (TAM-67), and pRL-SV40 expression plasmids have been previously described (Manna $e t$ al. 2004, 2006b). MA-10 cells (Ascoli 1981) were transfected using FuGENE HD-transfection reagent (Roche Diagnostics Corp.), under optimized conditions (Manna et al. 2004, Manna \& Stocco 2007). Briefly, the $-151 /-1$ STAR (wild type and mutant) reporters were transfected with different expression plasmids (1:1). Transfection with small interfering RNAs (siRNAs) was performed using X-tremeGENE siRNA transfection reagent (Roche Diagnostics Corp.), as described previously (Dyson et al. 2008). Silencer negative control siRNA and the JUN siRNAs (\#1, $5^{\prime}$-CAGUAACCCUAAGAUCCUA-3' ${ }^{\prime}$, and \#2, 5'-CCAAGUGCCGGAAAAGGAA-3 ${ }^{\prime}$ ) were obtained as annealed oligos from Ambion Inc., (Austin, TX, USA).

Luciferase activity in the cell lysates was determined by the Dual-luciferase reporter assay system (Promega), using a TD 20/20 Luminometer (Turner Designs, Sunnyvale, CA, USA), as described previously (Manna et al. 2002a, 2003a, Manna \& Stocco 2007).

\section{Immunoblotting}

Western blot analyses were carried out with total cellular protein (Manna et al. 2006a, 2007). Briefly, equal amounts of protein $(20-30 \mu \mathrm{g})$ were loaded on either 10 or 12\% SDS-PAGE (Mini Protean II System, Bio-Rad Laboratories Inc). The proteins were electrophoretically transferred onto Immuno-Blot polyvinylidene difluoride (PVDF) membranes (Bio-Rad), which were probed with the specific antibodies (Abs) that recognize JUN (sc-45, 1:2000), JUNB (sc-8051, 1:1000), JUND (sc-74, 1:1000), FOS (sc-8047, 1:2000), FOSB (sc48, 1:1000), FOSL1 (sc-183, 1:1000), FOSL2 (sc-171, 1:1000), actin (sc-7210, 1:1000; Santa Cruz Biotechnology, Santa Cruz, CA, USA), P-JUN (Ser ${ }^{63}$, 1:1500; Cell Signaling Technology Inc., Beverly, MA, USA), STAR (1:20 000; Bose et al. 1999), P-STAR (Ser ${ }^{194}, 1: 10$ 000; Manna et al. 2006b), and CYP11A1 (1:5000; Chemicon International Inc., Temecula, CA, USA). Horseradish peroxidase-conjugated secondary Abs against rabbit, mouse, or goat IgG were used to recognize relevant primary Abs. Immunodetection of different proteins was determined with the Chemiluminescence Imaging Western Lightning Kit (PerkinElmer, Boston, MA, USA). The membranes were exposed to X-ray films (Marsh Bio Products Inc., Rochester, NY, USA), and the intensity of immunospecific bands was quantified using a computer-assisted image analyzer (Visage 2000, BioImage, Ann Arbor, MI, USA). All western blotting experiments were repeated three to five times. 


\section{Electrophoretic mobility shift assay (EMSA)}

EMSA experiments were carried out with MA-10 nuclear extracts (NE) and in vitro transcribed/translated JUN (Manna et al. 2002a, 2003a, 2004). The sense strands of the oligonucleotide sequences used were the following: $-83 /-67$ wild type, 5 '-GGAATGACTGATGACTTTT-3'; $-83 /-67$ mutant $(-83 /-67 \mathrm{M})$, 5'-GGAATAGATCTTGACTTTT-3'; consensus JUN (Promega), 5'-CGCTTGATGAGTCAGCCGGAA-3' . The double-stranded oligonucleotide was end-labeled with $\left[\alpha^{32} \mathrm{P}\right]$-dCTP (Perkin-Elmer) using Klenow fill-in reaction, and DNA-protein-binding assays were carried out under optimized conditions (Manna et al. 2002a, 2004). Briefly, NE $(12 \mu \mathrm{g})$ and in vitro translated JUN $(2-5 \mu \mathrm{g})$ were incubated in $20 \mu \mathrm{l}$ reaction buffer (10 mM HEPES, $1 \mathrm{mM}$ EDTA, 4\% Ficoll, $10 \mathrm{mM}$ dithiothreitol, $1 \mu \mathrm{g}$ poly $\mathrm{dIdC}, 40 \mathrm{mg} / \mathrm{ml} \mathrm{BSA}$, and $2 \mu \mathrm{M} \mathrm{ZnSO}_{4}, \mathrm{pH} 7.9$ ) for $15 \mathrm{~min}$ at room temperature. The ${ }^{32}$ P-labeled DNA probe was added alone or in the presence of 100-fold molar excess of unlabeled sequence, and incubation was continued for another 15 min. When JUN (sc-45) and FOS (sc-8047) Abs were used, binding reactions were incubated on ice for $45 \mathrm{~min}$ prior to the addition of ${ }^{32} \mathrm{P}$-labeled DNA. Binding reaction was then subjected to electrophoresis on $5 \%$ polyacrylamide gels, which were dried, and the complexes were visualized using a phosphor imaging device (Molecular Dynamics, Sunnyvale, CA, USA). These experiments were repeated at least three times.

\section{Quantitative reverse transcription and PCR (RT-PCR)}

The isolation and amplification of mouse STAR (Clark et al. 1994) and JUN (GenBank accession number NM_010591) cDNAs were carried out using total RNA, as described previously (Manna et al. 1999, 2007). Briefly, the primer pairs used were: STAR sense, $5^{\prime}$-GACCTTGAAAGGCTCAGGAAGAAC- ${ }^{\prime}$, and STAR antisense, 5' ${ }^{\prime}$-TAGCTGAAGATGGACAGACTTGC-3'; JUN sense, 5'-GCTAACCCCCGTGAAGTGACGG-3' and JUN antisense, 5'-GTAGACCGGAGGCTCACTGTG-3' ${ }^{\prime}$. The variation in RT-PCR efficiency was assessed with an L19 ribosomal protein gene using the following primer pairs: L19 sense 5'-GAAATCGCCAATGCCAACTC-3' and L19 antisense $5^{\prime}$-TCTTAGACCTGCGAGCCTCA-3' (Chan et al. 1987). RT and PCR were run sequentially in the same assay tube using $2 \mu \mathrm{g}$ total RNA. The cDNAs generated were further amplified by PCR using the primer pairs listed above. The molecular sizes of STAR, JUN, and L19 were determined on $1.2 \%$ agarose gels, which were then vacuum dried, exposed to X-ray film (Marsh Bio Products), and the levels of different signals were quantified using a computerassisted image analyzer (Visage 2000).

\section{Chromatin immunoprecipitation (ChIP) assay}

ChIP assays were carried out using a kit (Upstate/ Chemicon) following the manufacturer's instructions, under optimized conditions (Manna \& Stocco 2007). Briefly, cells were incubated with formaldehyde to crosslink DNA and its associated proteins and sonicated in lysis buffer. Following centrifugation, the supernatant was immunoprecipitated with either P-JUN Ab (as above) or IgG for $14 \mathrm{~h}$ at $4{ }^{\circ} \mathrm{C}$. The chromatinantibody-protein A agarose complexes were washed subsequently with low salt, high salt, $\mathrm{LiCl}$, and Tris/ EDTA buffers. Protein-DNA complexes were eluted with freshly made elution buffer ( $1 \%$ SDS, $0 \cdot 1 \mathrm{M}$ $\mathrm{NaHCO}_{3}$ ), and then the eluted materials were incubated at $65^{\circ} \mathrm{C}$ for $4 \mathrm{~h}$ to reverse the formaldehyde cross-linking. The resulting samples were treated with $0.5 \mathrm{M}$ EDTA, $1 \mathrm{M}$ Tris-HCl $(\mathrm{pH} 6.5$ ), and $10 \mathrm{mg} / \mathrm{ml}$ proteinase $\mathrm{K}(10 \mathrm{mg} / \mathrm{ml})$ for $1 \mathrm{~h}$ at $45^{\circ} \mathrm{C}$, and the purified DNA samples were used for PCR using $\left[\alpha^{32} \mathrm{P}\right]$ dCTP in the dNTP mixture (Manna \& Stocco 2007). PCR was performed with $\sim 100 \mathrm{ng}$ of DNA and the proximal mouse STAR promoter primers: sense, $5^{\prime}$-CTGGTCCTCCCTTTACACAGTC- ${ }^{\prime}$, and antisense, 5'-GGCGCAGATCCAGTGCGCTGC-3' (Caron et al. 1997, Manna \& Stocco 2007). PCR products were determined on $2 \%$ agarose gels. Gels were vacuum dried, exposed to X-ray film (Marsh Bio Products), and the resulting signals were visualized by autoradiography. These experiments were repeated four times.

\section{JUN PathDetect transreporting assay}

MA-10 cells were transfected with the pathway-specific pFA2-JUN transactivator plasmid (Stratagene, La Jolla, CA, USA), in the presence of a pFR-Luc reporter, using FuGENE HD-transfection reagent (Roche Diagnostics Corp.), as described previously (Manna et al. 2006a,b). The transactivator protein consists of the activation domain of JUN (aa1-223) fused with the LGALS4 DNAbinding domain (aa1-147). The pFR-Luc plasmid contains a synthetic promoter of the yeast LGALS4binding sites that control the expression of the firefly luciferase gene. Cells were also co-transfected with JUN and TAM- 67 to determine the functional specificity of JUN. Following $36 \mathrm{~h}$ of transfection, cells were pretreated without or with GF-10923X (GFX) and then treated with phorbol 12-myristate 13-acetate (PMA) for an additional $6 \mathrm{~h}$, and luciferase activity in the cell lysates was determined using a TD 20/20 Luminometer (Turner Designs).

\section{Statistical analysis}

All experiments were repeated three to seven times. Statistical analysis was performed by ANOVA using 
Statview (Abacus Concepts Inc., Berkeley, CA, USA) followed by Fisher's protected least significant differences test. Data represent the mean \pm s.E.M. and $P<0.05$ was considered significant.

\section{Results}

\section{Effects of PMA on JUN and FOS expression, steroidogenesis, and on the JUN PathDetect assay}

The function of JUN on the PRKCC-mediated regulation of STAR expression and steroidogenesis was investigated using MA-10 cells. As illustrated in Fig. 1A, cells treated with PMA $(10 \mathrm{nM})$ for $6 \mathrm{~h}$ demonstrated a $3 \cdot 1 \pm 0 \cdot 5$-fold increase in the expression of JUN protein, when compared with untreated cells. Inhibition of PRKCC activity by GF10923X (GFX; $20 \mu \mathrm{M}$, (Jo et al. 2005, Manna et al. 2006 b 2007)) abolished PMA-induced JUN expression. Under similar experimental paradigms, while PMA induced a pronounced increase in JUN expression, it had varying effects, albeit lesser ones, on the protein levels of other JUN and FOS family members. In particular, PMA showed little to no effects on JUNB, FOSB, and FOSL2 levels but increased $(P<0 \cdot 05)$ JUND, FOS, and FOSL1 expression, when compared with their respective controls. On the other hand, treatment with PMA showed a $5 \cdot 6 \pm 1 \cdot 2$-fold increase in progesterone synthesis over basal levels $(1 \cdot 7 \pm$ $0.3 \mathrm{ng} / \mathrm{mg}$ protein), a response that was attenuated $\sim 75 \%$ by GFX (Fig. 1B). GFX alone had no apparent effects on either JUN and FOS expression or progesterone synthesis. The induction of JUN expression and steroid synthesis by PMA occurred maximally between 4 and $8 \mathrm{~h}$, decreased thereafter $(8-$ $12 \mathrm{~h})$, and was further decreased $(P<0 \cdot 01)$ at $24 \mathrm{~h}$, but was still higher than controls (data not shown). These findings suggest that among the different JUN and FOS members, JUN plays a predominant role in PRKCC-mediated steroid synthesis.

The involvement of PRKCC-responsive JUN expression was further verified using the pathwayspecific transreporting assay. Cells transfected with the pFA2-JUN transactivator plasmid demonstrated $1.9 \pm$ $0 \cdot 3-$ and $3 \cdot 7 \pm 0 \cdot 8$-fold increases in luciferase activity over basal in response to 5 and $10 \mathrm{nM}$ PMA respectively (Fig. 2). GFX in combination with PMA strongly decreased $(P<0 \cdot 01)$ PMA-induced responsiveness. Co-expression of pFA2-JUN and TAM-67 (a dominant negative mutant of JUN) inhibited basal- and PMAmediated luciferase activities by $55-70 \%$, clearly demonstrating the importance of JUN in the PRKCC signaling pathway.

To ascertain the involvement of JUN in PRKCC signaling, expression of JUN and its post-translational
A

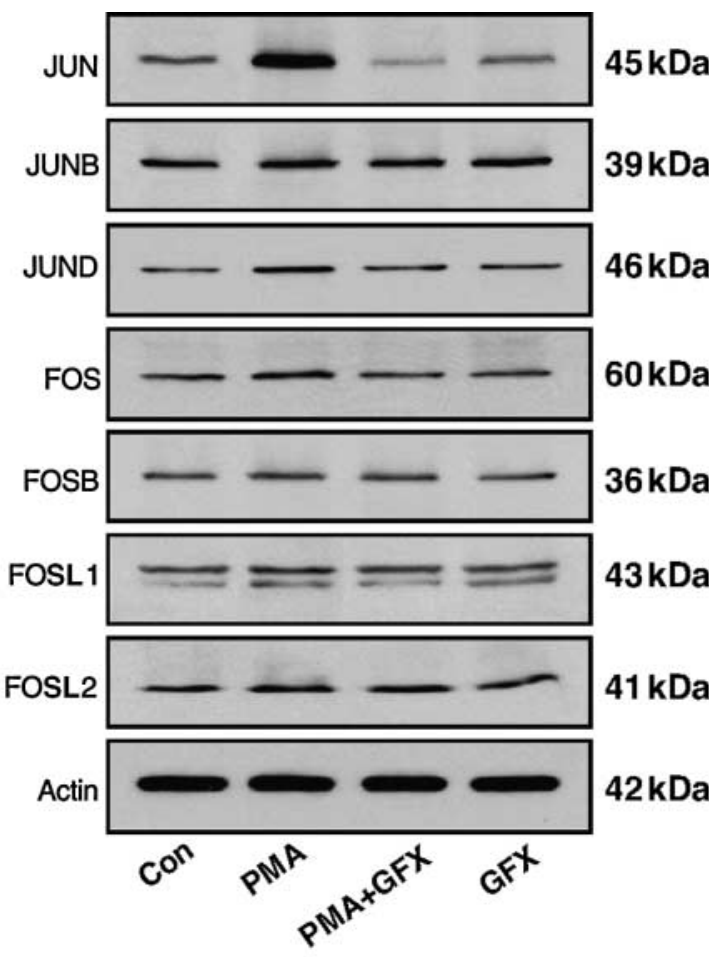

B

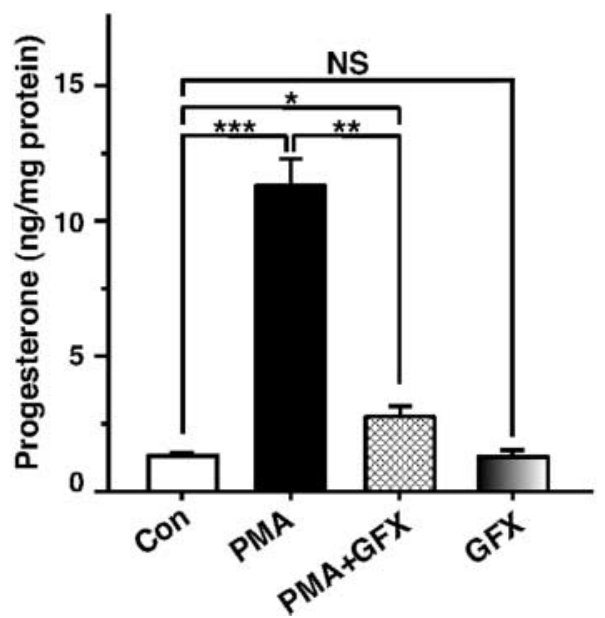

Figure 1 Effects of PMA on the expression of JUN and FOS proteins and steroid synthesis. (A) MA-10 cells were pretreated without or with GFX $(20 \mu \mathrm{M})$ for $30 \mathrm{~min}$, and then treated in the absence or presence of PMA (10 nM) for an additional $6 \mathrm{~h}$.

Expression of different JUN and FOS proteins was determined by western blotting using $25 \mu \mathrm{g}$ of total protein. Immunoblots shown are representative of three to five independent experiments. Actin expression was assessed as a loading control. Accumulation of progesterone in the media of the same treatment groups was determined and expressed as $\mathrm{ng} / \mathrm{mg}$ protein, which represent the mean \pm S.E.M. of five independent experiments (B). ${ }^{\star} P<0.05$; ${ }^{\star \star} P<0.01 ;{ }^{* \star *} P<0.001$; NS, not significant. 


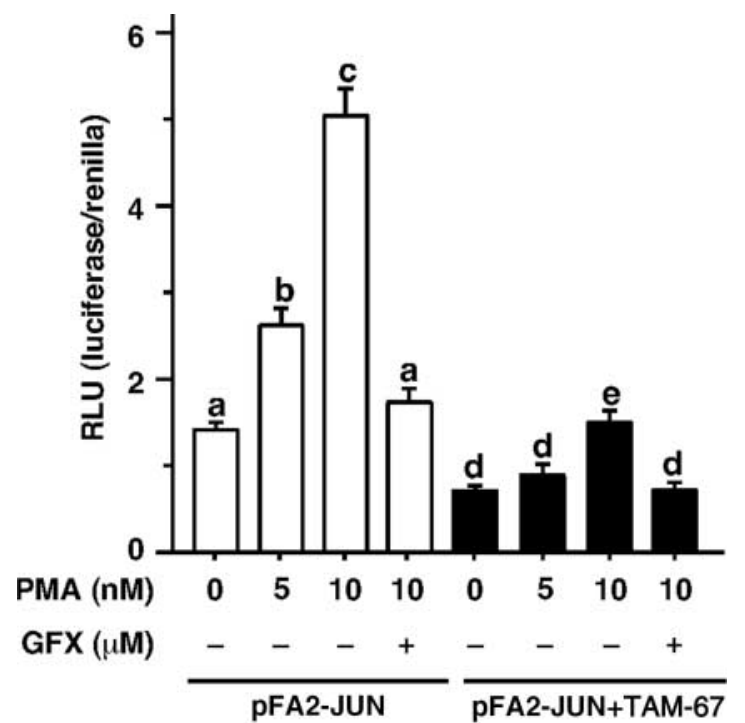

Figure 2 Role of PMA on JUN PathDetect transreporting assay. MA-10 cells were transfected with the pathway-specific pFA2JUN transactivator plasmid in the presence of pFR-Luc reporter, as described in Materials and methods. The pRL-SV40 was included in the transfection to normalize transfection efficiency. The specificity of JUN responsiveness was evaluated by co-expressing TAM-67 (a dominant negative mutant of JUN). Following $36 \mathrm{~h}$ of transfection, cells were pretreated for $30 \mathrm{~min}$ without or with GFX $(20 \mu \mathrm{M})$ and then incubated with two different doses of PMA ( 5 and $10 \mathrm{nM}$ ) for an additional $6 \mathrm{~h}$. Luciferase activity in the cell lysates was determined ( \pm S.E.M., $n=7)$ and expressed as relative light units (RLU; luciferase/renilla). Letters above the bars indicate that these groups differ significantly from each other at least at $P<0.05$.

modification following phosphorylation were evaluated. Cells treated with PMA (10 nM) showed 2.9- and $3 \cdot 2 \pm 0 \cdot 5$-fold increases in JUN expression and JUN phosphorylation (P-JUN, Ser $^{63}$ ) over untreated cells respectively, demonstrating that the increases in JUN expression and its phosphorylation in response to PMA were similar (Fig. 3A and B). While GFX abrogated PMA-induced JUN and P-JUN levels, a PRKACA inhibitor H-89 (20 $\mu \mathrm{M}$, (Jo et al. 2005, Manna et al. 2006b, 2007)) had no effects on these parameters, suggesting the specificity of JUN in PRKCC signaling. Likewise, PMA demonstrated an $8 \cdot 3 \pm 0 \cdot 9$-fold increase in STAR protein expression over basal. Notably, while H-89 had no effects on JUN and P-JUN levels, both GFX and H-89 attenuated $(P<0 \cdot 01)$ PMA-responsive STAR expression and progesterone (not illustrated) synthesis, suggesting an involvement of signaling crosstalk between PRKACA and PRKCC in the steroidogenic response (Fig. $3 \mathrm{~A}$ and $\mathrm{B}$ ). Consistent with our previous findings, phosphorylation of STAR ( $\mathrm{Ser}^{194}$, P-STAR) was undetectable in any of these treatments (data not shown; Jo et al. 2005, Manna et al. 2006b, 2007).
To better understand signaling events, the effects of PRKCG on JUN, STAR, CYP11A1, and steroid levels were determined. Cells treated with PMA $(0-50 \mathrm{nM})$ demonstrated increases in the expression of JUN, STAR, CYP11A1, and progesterone levels in a concentration-dependent manner (Fig. 3C). The magnitude of responses at $10 \mathrm{nM}$ PMA was $\sim 2 \cdot 7-, 8 \cdot 7-, 1 \cdot 9-$, and $5 \cdot 3$-fold on JUN, STAR, CYP11A1 proteins, and progesterone synthesis, when compared with their respective controls. The lower than expected fold increase $(P<0 \cdot 05)$ in the level of CYP11A1 protein observed in response to PMA was in all likelihood a result of its higher basal expression (Ilvesmaki \& Voutilainen 1991, Bird et al. 1995), which may be critical in producing the increased level of progesterone observed in PMA-treated cells. These findings also indicate that the unexpectedly small increase in progesterone production associated with the marked induction of STAR expression by PMA was due to the lack of STAR phosphorylation.

In additional studies, the influence of PMA on $(\mathrm{Bu})_{2} \mathrm{cAMP}$-stimulated JUN expression and steroidogenesis was studied, since PRKCC has been demonstrated to enhance PRKACA responsiveness in different steroidogenic cells (Tilly \& Johnson 1989, Jo et al. 2005, Manna et al. 2006a,b, 2007). MA-10 cells treated with PMA $(10 \mathrm{nM})$ for $6 \mathrm{~h}$ demonstrated a 2.8-fold increase in JUN expression over untreated cells; however, its level was unaffected in response to a suboptimal dose $(0 \cdot 1 \mathrm{mM})$ of $(\mathrm{Bu})_{2}$ cAMP (Fig. $\left.4 \mathrm{~A}\right)$. The concentration of $(\mathrm{Bu})_{2} \mathrm{cAMP}$ chosen was based on previous findings; however, it is noted that $(\mathrm{Bu})_{2} \mathrm{CAMP}(0 \cdot 5 / 1.0 \mathrm{mM})$ was shown to have no effect on JUN expression but it attenuated P-JUN level below controls at $6 \mathrm{~h}$ (Clem et al. 2005, Jo et al. 2005, Manna et al. 2007, Manna \& Stocco 2007). Addition of PMA to $(\mathrm{Bu})_{2}$ cAMP-treated cells produced a $1 \cdot 8 \pm 0 \cdot 3$ increase in JUN expression over the response seen with PMA alone, suggesting the involvement of additional factor(s) in this process since $(\mathrm{Bu})_{2} \mathrm{cAMP}$ has no effect on JUN expression. On the other hand, both PMA and $(\mathrm{Bu})_{2}$ cAMP alone increased STAR expression and progesterone synthesis over their respective basal levels. However, cells treated with PMA and $(\mathrm{Bu})_{2} \mathrm{cAMP}$ together dramatically augmented STAR, P-STAR, and progesterone levels when compared with their responses individually (Fig. 4A and $\mathrm{B})$. The combined effects of PMA and $(\mathrm{Bu})_{2} \mathrm{cAMP}$ on JUN, STAR, P-STAR, and progesterone levels were significantly affected $(P<0 \cdot 05)$ both by GFX and H-89. Whereas these inhibitors markedly attenuated STAR expression and steroid synthesis when the cells were co-treated with PMA and $(\mathrm{Bu})_{2}$ cAMP, the effect of $\mathrm{H}-89$ was more pronounced than GFX, indicating that intracellular cAMP plays an important role in regulating PRKCC/PRKACA-dependent steroidogenesis. 
A

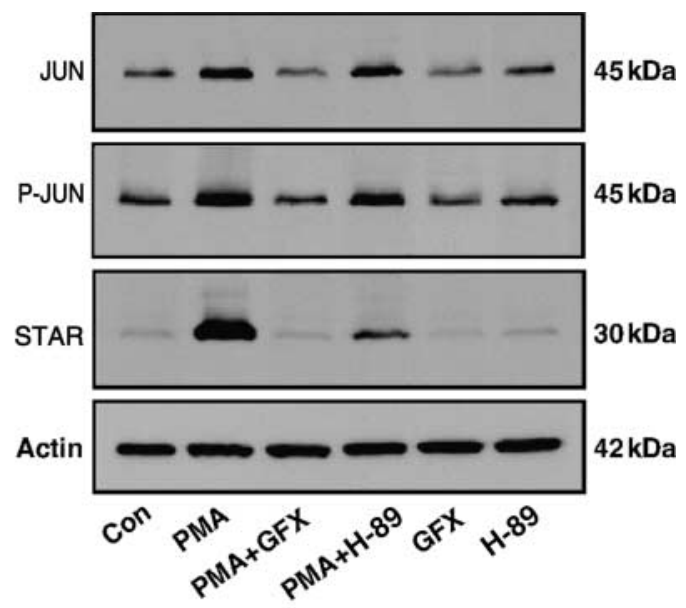

B

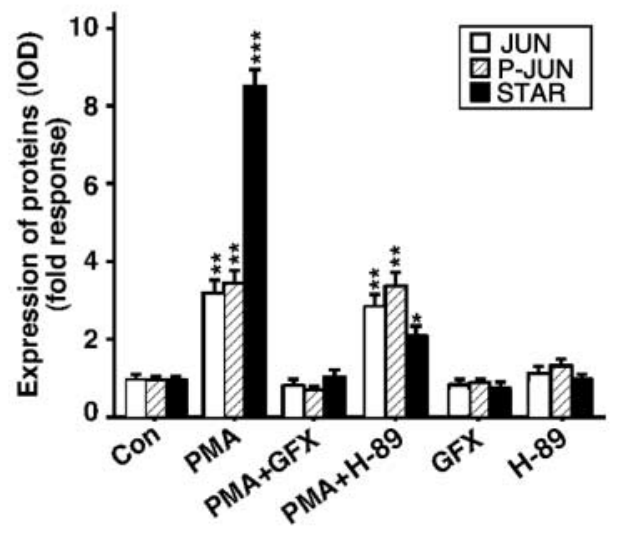

C
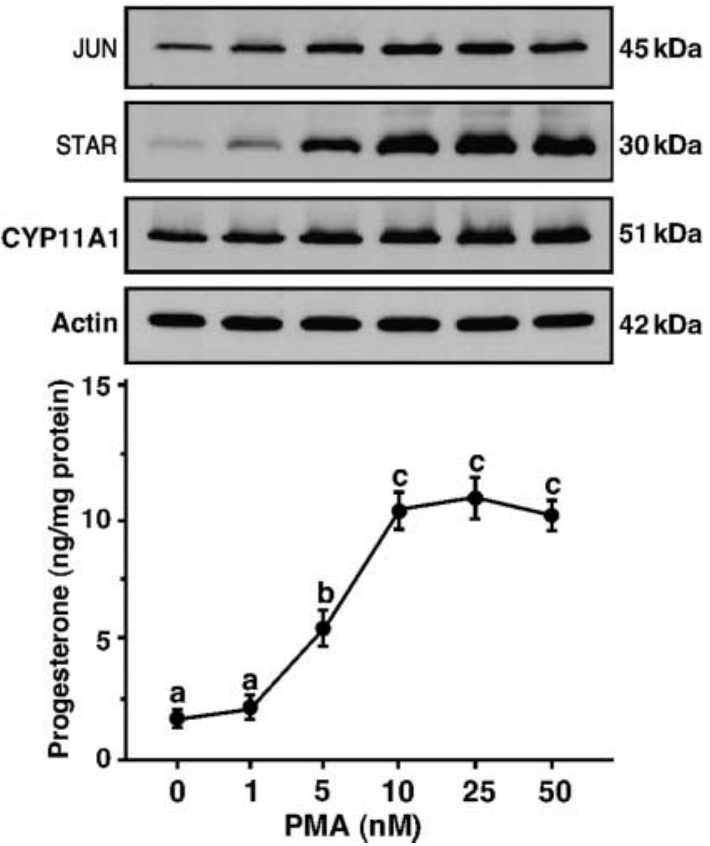

Induction of PRKCC-mediated JUN expression and steroid synthesis requires de novo protein synthesis

The effect of PRKCC on JUN expression and its relevance to steroid synthesis was studied for its dependence on protein synthesis. As depicted in Fig. 5, MA-10 cells treated with PMA $(10 \mathrm{nM})$ showed a $3 \cdot 5 \pm 1 \cdot 1$-fold increase in Jun mRNA expression. Addition of the protein synthesis inhibitor, cycloheximide $(\mathrm{Chx}, 5 \mu \mathrm{M})$, to PMAtreated cells significantly inhibited $(P<0 \cdot 01)$ Jun gene expression (Fig. 5A and B). Chx alone had no effect on Jun mRNA expression. Progesterone production in the media increased 5.8-fold in response to PMA and this response was decreased $\sim 80 \%$ by Chx (Fig. $5 \mathrm{~B}$ ). These results demonstrate a link between JUN and steroid synthesis and indicate that the induction of PMAmediated JUN expression and steroid synthesis is dependent on translation in these cells.

\section{Interaction of JUN with the JUN motif in the STAR promoter and its consequences on Star gene expression}

To understand molecular events, the involvement of JUN in PRKCC-mediated regulation of the steroidogenic response was assessed using ChIP assays. It can be clearly seen from Fig. $6 \mathrm{~A}$ that cells treated with varying doses of PMA $(0-50 \mathrm{nM})$ demonstrated increases in P-JUN association with the STAR proximal promoter in a dose-responsive manner, reaching a maximum of $2 \cdot 7 \pm 0 \cdot 4$-fold at $10 \mathrm{nM}$, decreasing slightly at $50 \mathrm{nM}$, but remaining elevated over control. Figure $6 \mathrm{~B}$ demonstrated that the induction of PMA-mediated association of P-JUN with the STAR promoter was markedly decreased $(P<0 \cdot 01)$ by GFX. No signals were observed using DNA recovered from IgG-treated groups. These findings document the physical interaction of

Figure 3 Effects of PMA on JUN, P-JUN, STAR, CYP11A1, and steroid levels. MA-10 cells were pretreated without or with GFX $(20 \mu \mathrm{M})$ and $\mathrm{H}-89(20 \mu \mathrm{M})$ for $30 \mathrm{~min}$, and then treated in the absence or presence of PMA $(10 \mathrm{nM})$ for a further $6 \mathrm{~h}$, as indicated. Expression of JUN, P-JUN, and STAR in the cell lysates ( $22 \mu \mathrm{g}$ of protein) was determined by western blotting $(A)$. Immunoblots shown are representative of three to four independent experiments. Integrated optical density (IOD) values of each band were quantified and compiled data ( \pm S.E.M., $n=3$ ) are presented $(B)$. Cells were also treated with increasing doses of PMA (0-50 nM) for $6 \mathrm{~h}$, and levels of JUN, STAR, and CYP11A1 were determined by immunoblotting using $25 \mu \mathrm{g}$ of total protein (C). Actin expression (A and C) was assessed as loading controls. Progesterone synthesis in the media of the same treatment groups was determined and expressed as $\mathrm{ng} / \mathrm{mg}$ protein, which represent the mean \pm s.E. of three independent experiments $(C)$. Letters above the bars indicate that these groups differ significantly from each other at least at $P<0.05$. ${ }^{\star} P<0.05$; ${ }^{\star \star} P<0.01 ;{ }^{* \star} P<0.001$ versus respective controls. 


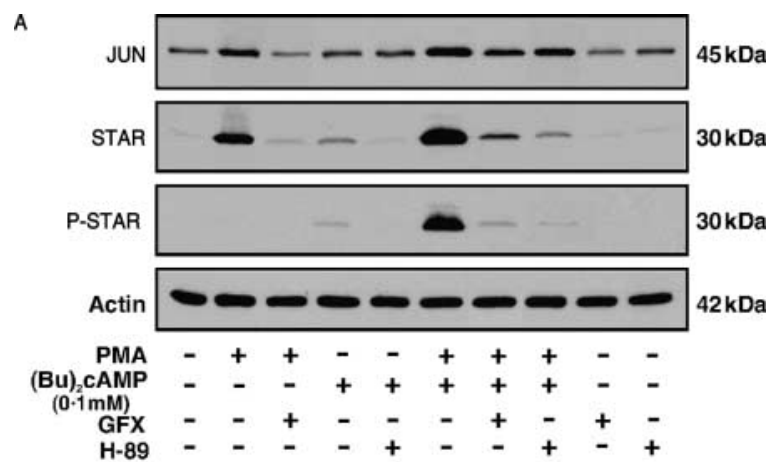

B

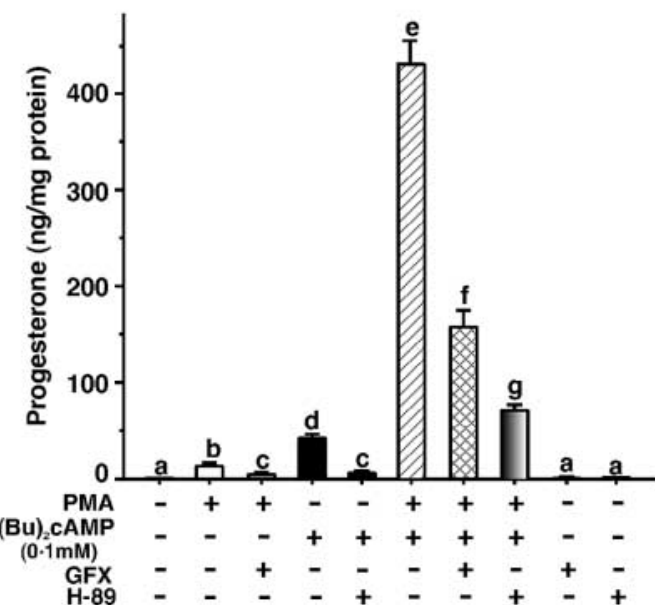

Figure 4 Effects of PMA and $(\mathrm{Bu})_{2} \mathrm{cAMP}$ on the expression of JUN, STAR, P-STAR, and progesterone levels in MA-10 cells.

Cells were pretreated either with GFX $(20 \mu \mathrm{M})$ or $\mathrm{H}-89(20 \mu \mathrm{M})$ for 30 min, and then treated in the absence or presence of PMA $(10 \mathrm{nM}),(\mathrm{Bu})_{2} \mathrm{CAMP}(0.1 \mathrm{mM})$, or a combination of both for a further $6 \mathrm{~h}$, as indicated $(\mathrm{A})$. These experiments were repeated four times, and representative immunoblots illustrate JUN, STAR, and P-STAR levels using $25 \mu \mathrm{g}$ total protein. Actin expression was assessed as a loading control. (B) Accumulation of progesterone in the media of the same treatment groups was determined and expressed as $n g / m g$ protein ( \pm s.E.M., $n=4$ ). Letters above the bars indicate that these groups differ significantly from each other at least at $P<0.05$.

P-JUN-DNA with the STAR promoter following the activation of PRKCC signaling.

To obtain more insight into these mechanisms, EMSA DNA-protein binding was carried out using MA-10 NE and in vitro transcribed/translated JUN. As shown in Fig. 7A, a ${ }^{32}$ P-labeled probe $(-83 /-67)$ encompassing the JUN region of the STAR promoter resulted in the formation of two DNA-protein complexes (I and II) with untreated MA-10 NE (lane 2). PMA (10 nM) treatment further increased DNAprotein complex formation (compare lanes 2 and 3). DNA-protein binding was strongly inhibited by its unlabeled sequence (lane 4). An Ab that recognizes
A
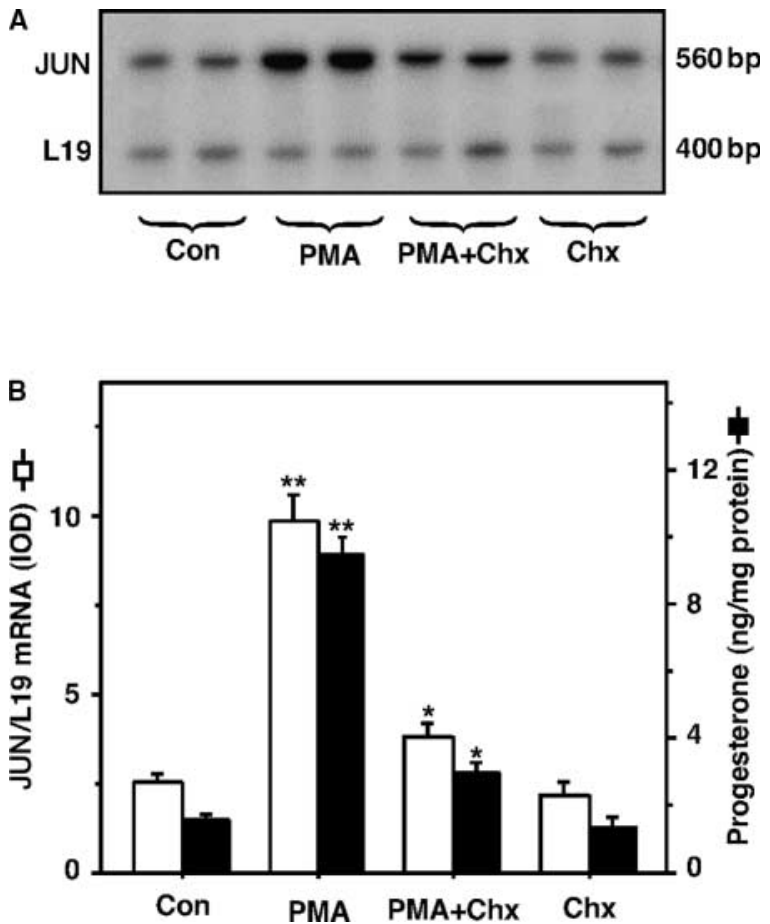

Figure 5 Induction of PMA-mediated Jun mRNA expression and progesterone production requires ongoing protein synthesis. MA10 cells were treated (in duplicates) without (Con) or with PMA

(10 nM), PMA plus cycloheximide (Chx; $5 \mu \mathrm{M})$, and Chx alone for $6 \mathrm{~h}$, and subjected to Jun mRNA expression by RT-PCR analysis (A). A representative autoradiogram illustrates the expression of Jun and L19 mRNAs in different treatment groups using $2 \mu \mathrm{g}$ total RNA. IOD values of each band were quantified and normalized to the corresponding L19 bands (B). Accumulation of progesterone in the media was determined and expressed as $\mathrm{ng} / \mathrm{mg}$ protein $(\mathrm{B})$. Results represent the mean \pm S.E.M. of four independent experiments. Note the different scales on the graph. ${ }^{\star} P<0.05 ;{ }^{\star \star} P<0.01$ versus respective controls.

JUN in immunoblots diminished DNA-protein complexes (lane 6), suggesting that MA-10 NE binding to the $-83 /-67$ region is predominantly JUN protein. JUN proteins heterodimerize with FOS members, and FOS is reported to be the best-known partner of JUN (Angel \& Karin 1991). FOS Ab showed a decrease $(P<0.05)$ in DNA-protein binding (lane 5). In additional experiments (Fig. 7B), the $-83 /-67$ probe illustrated the presence of a specific DNAprotein complex (I) with in vitro translated JUN (lanes 2-6) and that the binding was increased with a higher amount of JUN (compare lanes 2 and 3). Unlabeled consensus JUN (Con JUN, lane 4) and JUN Ab (lane 5) nearly abolished formation of the DNA-protein complex. Binding was not affected with an unlabeled sequence containing JUN mutant $(-83 /-67 \mathrm{M}$, lane 6), suggesting that JUN binds to the JUN region of the STAR promoter and plays an important role in regulating Star gene transcription. 

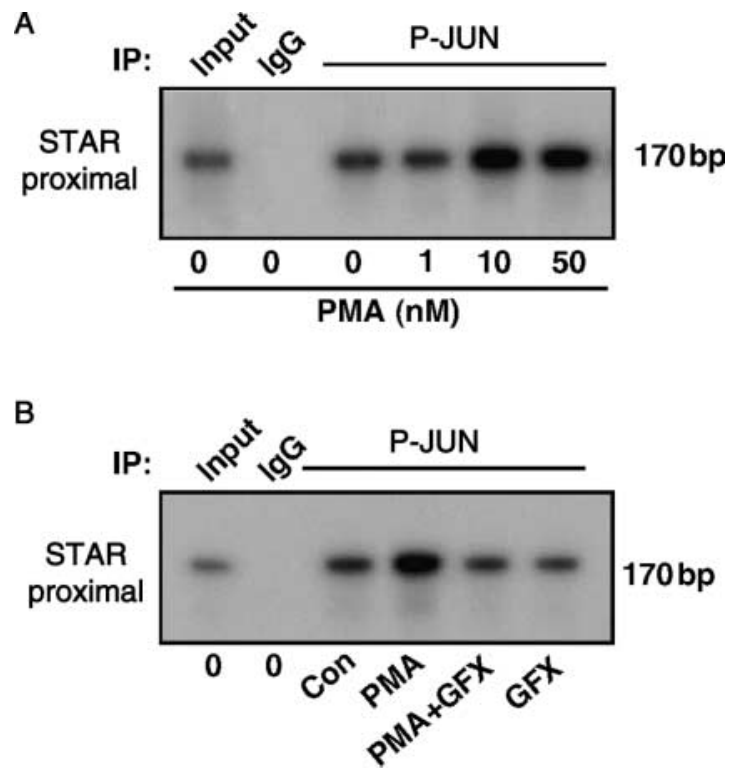

Figure 6 Effect of PMA on the association of JUN with the STAR promoter. MA-10 cells were pretreated without or with GFX $(20 \mu \mathrm{M})$ for $30 \mathrm{~min}$ and then incubated with either increasing $(0-50 \mathrm{nM} ; \mathrm{A})$ or a fixed dose $(10 \mathrm{nM}$; B) of PMA for $6 \mathrm{~h}$ as indicated, and ChIP assays were carried out as described in Materials and methods. Cross-linked sheared chromatin obtained from control (Con) and PMA treatments were immunoprecipitated (IP) with anti-P-JUN or IgG. Recovered chromatin was subjected to $\mathrm{PCR}$ analysis using primers ( $-170 /-1 \mathrm{bp})$ encompassing the JUN region of the STAR promoter. Autoradiograms shown are representative of three to five independent experiments.

\section{The functional relevance of JUN in PRKCC-mediated STAR expression and steroid synthesis}

The impact that JUN has on PRKCC-mediated STAR expression and steroidogenesis was further elucidated utilizing overexpression and silencing approaches. MA10 cells transfected with the $-151 /-1$ bp STAR reporter plasmid (JUN Wt) displayed a $1 \cdot 9 \pm 0 \cdot 3$-fold increase in luciferase activity in response to PMA (Fig. 8A). This segment was chosen based on our previous studies (Manna et al. 2002a, 2004). Disruption of the JUN element (JUN Mut) resulted in an $\sim 50 \%$ decrease in STAR reporter activity, suggesting the importance of the JUN motif in PRKCC-mediated STAR promoter responsiveness. Cells transfected with the JUN expression plasmid (JUN), within the context of the $-151 /-1 \mathrm{bp}$ STAR fragment, demonstrated an additional $2 \cdot 4 \pm 0 \cdot 5$-fold increase in luciferase activity over the response seen with PMA in mock-transfected cells (Fig. 8B). GFX markedly decreased PMA-induced STAR reporter activity. The transactivation potential of JUN in PMA-mediated STAR reporter activity was strongly attenuated by TAM-67, demonstrating that JUN plays a key role in PRKCC-dependent transcription of the Star gene.
The results obtained with JUN overexpression were further corroborated with endogenous JUN knockdown studies. As illustrated with western blot (Fig. 9A), and RT-PCR (Fig. 9B), analyses, MA-10 cells transfected with $100 \mathrm{nM}$ of either of the two JUN-specific siRNAs (JUN siRNA \#1 and \#2) decreased basal JUN protein and Jun mRNA levels between 75 and 95\%, and concomitantly inhibited PMA-induced responsiveness when compared with a silencer negative control siRNA (Con siRNA). Star mRNA expression (Fig. 9B) and progesterone synthesis (Fig. 9C) under basal and PMA-stimulated conditions followed similar patterns to those of JUN levels, and were decreased by $45-55 \%$. Collectively, these findings demonstrate that JUN binds to the JUN motif in the STAR promoter and mediates PRKCC-mediated steroid synthesis by controlling the transcription of the Star gene in mouse Leydig cells.

\section{Discussion}

Regulation of steroid biosynthesis in Leydig cells is largely mediated through the interaction of LH/hCG to its specific receptor, which results in several intracellular modifications including the activation of cAMP-dependent PRKACA and the phosphorylation of proteins. Ligand-receptor interaction also stimulates phospholipase $\mathrm{C}$ and triggers the activation of the downstream PRKCC pathway that has been demonstrated to be involved in regulating STAR expression and steroid synthesis in Leydig cells (Jo et al. 2005, Manna \& Stocco 2005, Stocco et al. 2005). The present studies extend these observations by elucidating the molecular events in which the JUN transcription factor JUN acts to drive PRKCC-dependent STAR expression and steroidogenesis in mouse Leydig cells.

Our findings demonstrate that the activation of PRKCC signaling by PMA increases the expression and phosphorylation of JUN, events that are in close coordination with the expression of STAR and CYP11A1 and the synthesis of progesterone. Induction of Jun gene expression and steroid synthesis in response to PRKCG was effectively inhibited by cycloheximide, indicating a requirement for de novo protein synthesis. Inhibition of PRKCC, but not PRKACA, essentially abolished JUN/P-JUN expression, indicating the specificity of JUN in the PRKCC signaling pathway. However, PRKCC is a weak inducer of progesterone synthesis in MA-10 cells, an observation in agreement with previous findings that demonstrated moderate effects of PRKCC on steroid synthesis and on the expression of several steroidogenic enzymes, including CYP11A1 in different steroidogenic cells (Chaudhary \& Stocco 1988, Ilvesmaki \& Voutilainen 1991, Bird et al. 1995, Jo et al. 2005, Manna et al. 2006b, 2007). We have previously reported 
A
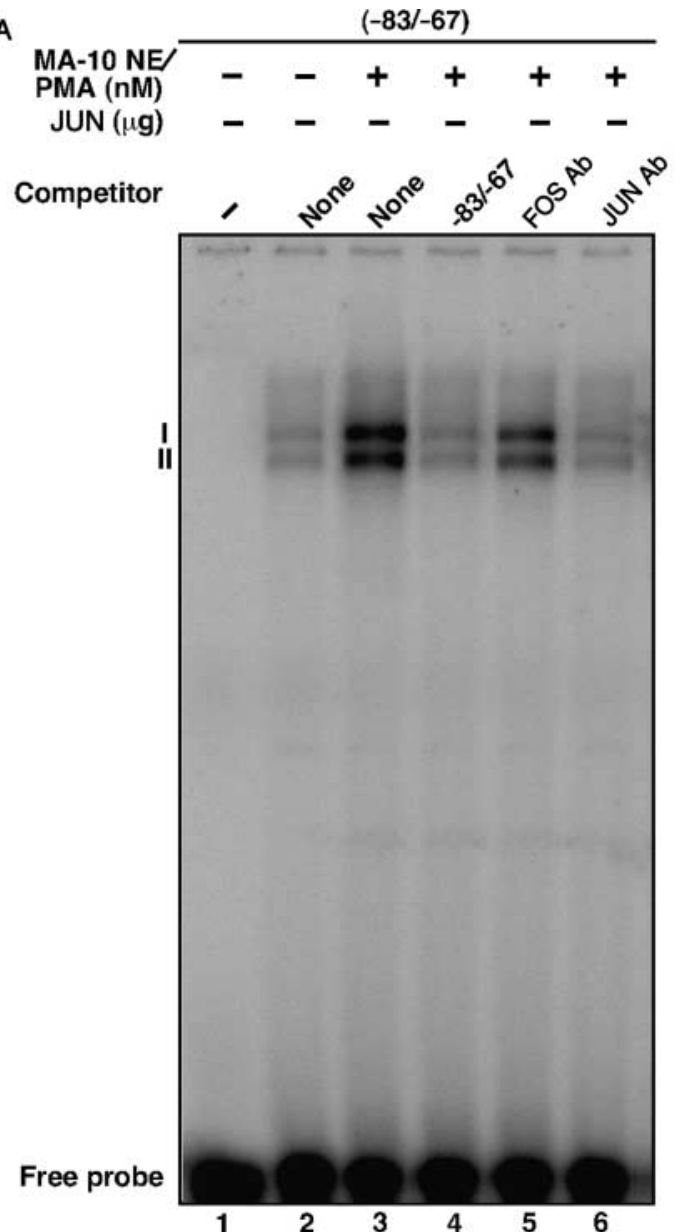

B
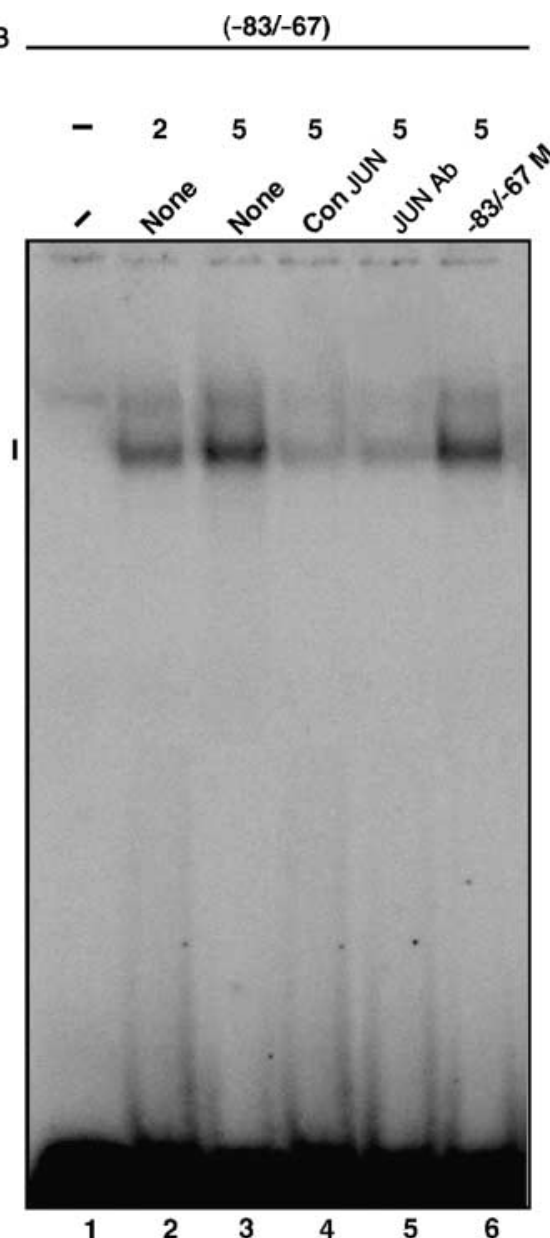

Figure 7 Binding of the JUN region in the STAR promoter to MA-10 NE and to in vitro translated JUN, using EMSAs. NE $(12 \mu \mathrm{g})$ obtained from control (lane 2) and PMA (10 nM) treated (lanes 3-6) MA-10 cells were incubated with the ${ }^{32} \mathrm{P}$-labeled probe specific to the JUN region $(-83 /-67)$ of the STAR promoter (A). DNA-protein complexes (labeled as I and II) were challenged with its unlabeled sequences (lane 4), FOS Ab (lane 5), and JUN Ab (lane 6). Binding of in vitro translated JUN (lanes 2-6) was also evaluated with the $-83 /-67$ probe (B). DNA-protein complex (labeled as I) was challenged with unlabeled consensus JUN (Con JUN, lane 4), JUN Ab (lane 5), and mutant JUN (-83/-67 M, lane 6) sequences. Cold competitors were used at 100 -fold molar excess. Migration of free probes is shown. These experiments were repeated three to four times, and representative phosphor images from each group are illustrated.

that steroid synthesis elicited by PRKCC is compromised by the obligatory need for PRKACA to phosphorylate and activate STAR in mouse Leydig cells (Jo et al. 2005, Manna et al. 2006b, 2007). In addition to stimulation of steroidogenesis by PRKCC, inhibitory effects of PRKCC on gonadal and adrenal steroid biosynthesis have also been demonstrated reviewed in Ref. Stocco et al. (2005). The differential effects of PRKCC in steroidogenesis thus appear to depend on tissue specificity, ligand concentrations, receptorligand interactions, and the short- or long-term experimental conditions.

Whereas the inhibition of PRKACA by H-89 was found to have no effects on PRKCC-mediated JUN and
P-JUN levels, it markedly affected STAR, P-STAR, and steroid synthesis. PMA does not elevate intracellular cAMP (Chaudhary \& Stocco 1988, Muller et al. 1998); therefore, the repression of PRKCC-mediated STAR expression and steroid synthesis by a PRKACA inhibitor strongly indicates the involvement of crosstalk in these signaling pathways. We demonstrate that PMA is capable of potentiating $(\mathrm{Bu})_{2}$ cAMP-induced JUN, STAR, P-STAR, and steroid levels, which reinforces the probability that PRKCC potentiates the activity of PRKACA that is involved in regulating steroidogenesis (Tilly \& Johnson 1989, Jo et al. 2005, Manna et al. 2006a,b, 2007). The observation that inhibition of PRKACA activity decreased the steroidogenic response 

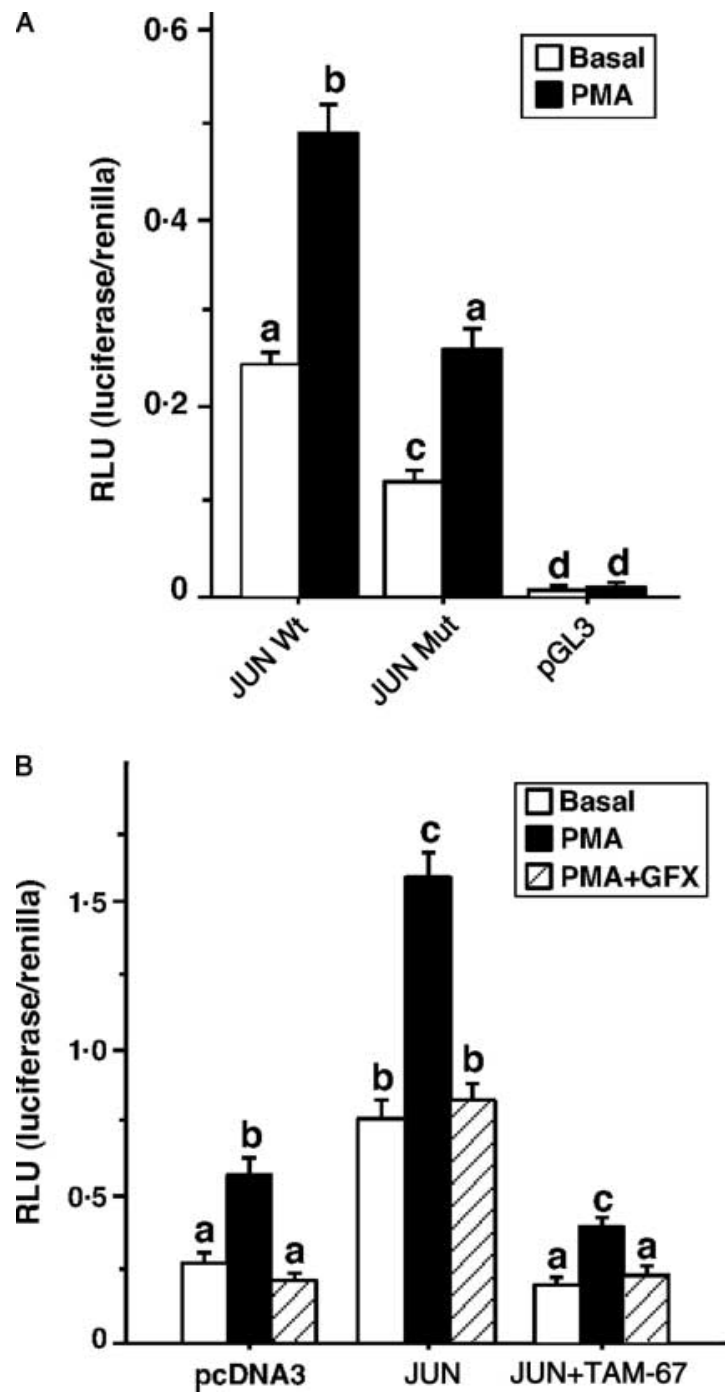

Figure 8 Functional involvement of the JUN element on Stargene expression. (A) MA-10 cells were transfected with either the $-151 /-1$ bp STAR reporter segment (JUN Wt) or the $-151 /-1$ containing a mutation in the JUN Mut, in the presence of $p R L-$ SV40 (renilla/luciferase for determining transfection efficiency). pGL3 basic (pGL3) was used as a control. Utilizing the $-151 /-1$ STAR reporter segment, cells were also transfected with empty vector (pcDNA3), wild type JUN, or JUN plus TAM-67 as indicated, in the presence of pRL-SV40 (B). Following $36 \mathrm{~h}$ of transfection, cells were pretreated without or with GFX $(20 \mu \mathrm{M})$ for $30 \mathrm{~min}$, and then incubated in the absence (basal) or presence of PMA (10 nM) for a further $6 \mathrm{~h}$. Luciferase activity in the cell lysates was determined and expressed as RLU (luciferase/renilla). Results represent the mean \pm S.E. of five independent experiments. Letters above the bars indicate that these groups differ significantly from each other at least at $P<0.05$.

mediated by PMA could indicate that the synergistic effects of PMA and $(\mathrm{Bu})_{2}$ CAMP on STAR, P-STAR, and steroid levels require the involvement of endogenous cAMP (Jo et al. 2005, Manna et al. 2006b, 2007). On the other hand, further increases in PMA-mediated JUN
A

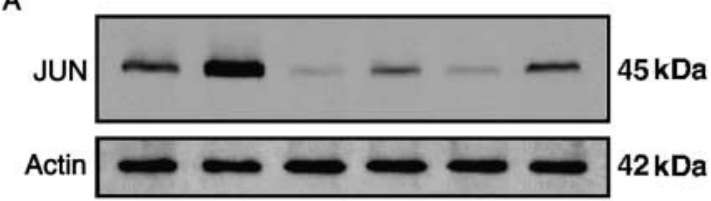

B
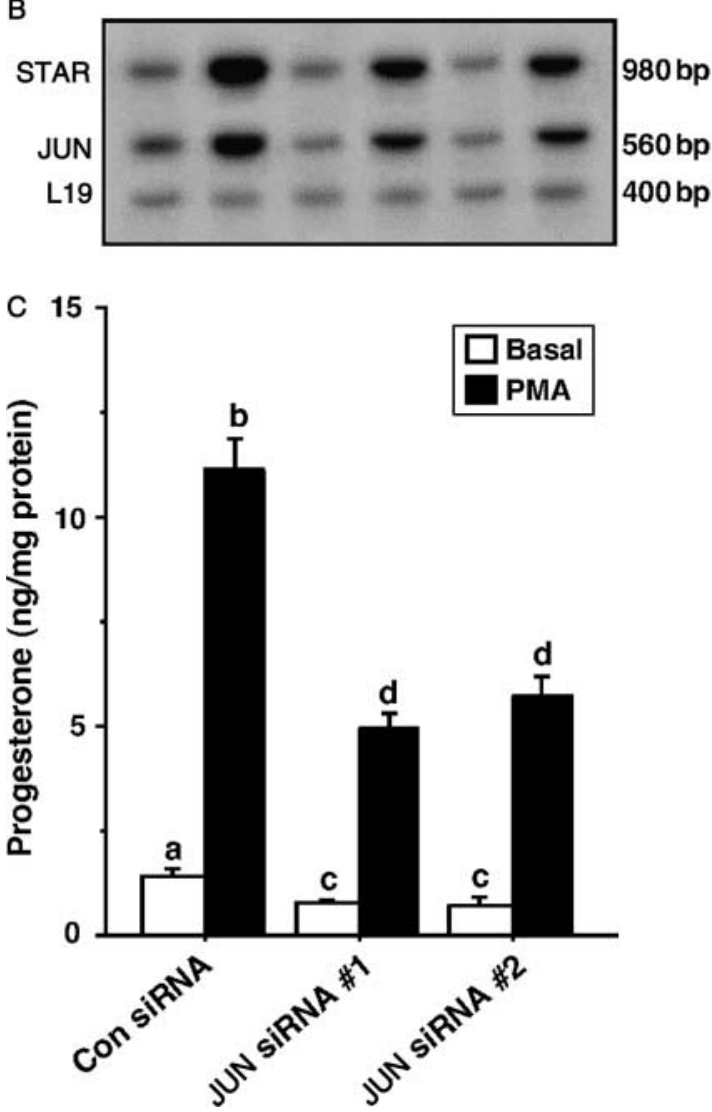

Figure 9 Silencing of JUN and its relevance to STAR expression and progesterone synthesis. MA-10 cells were transfected with either a negative control siRNA (Con siRNA) or two JUN-specific siRNAs (JUN siRNA \#1 \& \#2) at $100 \mathrm{nM}$ concentrations, as described in Materials and methods. Following $40 \mathrm{~h}$ of transfection, cells were treated without (basal) or with PMA (10 nM) for an additional $6 \mathrm{~h}$, and subjected to western blot (A) and RT-PCR (B) analyses. Representative immunoblots and autoradiogram illustrate the expression of JUN and actin (western blot) and JUN, STAR, and L19 (RT-PCR) in different treatment groups respectively. Actin and L19 were used as loading controls. Similar results were obtained from three independent experiments. (C) Accumulation of progesterone in the media of the same treatment groups was determined ( \pm s.E.M., $n=3$ ). Letters above the bars indicate that these groups differ significantly from each other at least at $P<0.05$.

levels in the presence of $(\mathrm{Bu})_{2} \mathrm{cAMP}$ suggests that additional factor(s) may be involved in these signaling pathways, since the latter had no effect on JUN expression. Previously, we have demonstrated that cAMP-dependent factors, while unable to enhance intracellular cAMP by themselves, are capable of 
enhancing hCG-mediated cAMP levels in mouse Leydig cells (Manna et al. 2006a,b). The role of PRKACA in ongoing steroid synthesis has been demonstrated by using different PRKACA inhibitors and speculated on a mechanism for the crosstalk between different signaling pathways in steroidogenic cells via guanine nucleotide exchange factors (Chin \& Abayasekara 2004). Nonetheless, PMA has been demonstrated to decrease the expression of a negative regulatory factor DAX-1 (dosage-sensitive sex reversal, adrenal hypoplasia congenita, critical region on the $\mathrm{X}$ chromosome, gene 1), and simultaneously increase extracellular signal-regulated kinase $1 / 2$ and CREB1 signaling, situations that have positive effects on STAR and steroid synthesis (Jo et al. 2005, Manna et al. 2006a,b, 2007). Therefore, a balance between the repressor and inducer functions generated through PRKCC activity may allow for fine tuning the steroidogenic machinery in mouse Leydig cells.

The previous identification of a JUN element (Manna et al. 2004) in the cAMP-responsive region of the mouse STAR promoter provided the opportunity to delineate the relevance of JUN in PRKCC-mediated Star gene expression. We demonstrate that the disruption of the JUN-binding site resulted in the repression of basal and PMA-dependent Star gene expression, which reinforces the involvement of JUN and FOS in the transcription of the Star gene in previous findings (Manna et al. 2002b, 2004, Shea-Eaton et al. 2002, Jo et al. 2005, Manna \& Stocco 2007). Nevertheless, an oligonucleotide probe encompassing the JUN motif can specifically bind MA-10 NE in a PRKCC-responsive manner as well as in vitro translated JUN, and that DNAprotein binding was affected by mutations in the JUN site, JUN Ab, and consensus JUN. It is noteworthy that the JUN motif in the STAR promoter is analogous to a CRE-like element that interacts with CRE-DNA-binding proteins (Manna et al. 2002a, 2003a). Similar overlapping sequences have been shown to target the CCAAT/ enhancer-binding protein $\beta$ (Silverman et al. 1999, 2006). Therefore, three families of proteins can bind to this region, a phenomenon that is perhaps not surprising since they share bZIP motifs and possess high degrees of homology in their DNA-binding domains. Members of these families can form selective dimers depending on the dimer composition and can alter their DNA-binding specificities in diverse physiological responses (Benbrook \& Jones 1990, Hai \& Curran 1991, Rutberg et al. 1999, Manna \& Stocco 2007). Consistent with this, the binding of MA-10 NE to the JUN motif was inhibited by FOS Ab, indicating the prevalence of cross-family dimerization (Manna $e t$ al. 2004). Moreover, JUN-DNA-binding activity correlated with the induction of JUN/P-JUN in response to PRKCC. In vivo ChIP data revealed that PMA increased the association of P-JUN with the STAR proximal promoter. We and others have shown that treatment with cAMP analog increases the binding of several transcription factors, including JUN/P-JUN, to the proximal but not the distal, STAR promoter, that occurs concurrently with the co-regulator CREB1-binding protein (CBP; Hiroi et al. 2004, Clem et al. 2005, Manna \& Stocco 2007). CBP and its functional homolog, p300, are recognized as bridging proteins, involved in the communication between transcription factors and the basal transcriptional machinery, and have been shown to participate in the activities of many transcription factors including JUN/FOS (Bannister et al. 1995, Vo \& Goodman 2001, Manna \& Stocco 2007). Hence, it is plausible that the PRKCC-mediated induction of P-JUN results in the recruitment of CBP to function in regulating Star gene transcription.

In view of the present studies, it is apparent that the JUN transcription factor JUN plays an essential role in the PRKCC-mediated regulation of STAR expression and steroidogenesis. In support of this, the JUN protooncogene, but not other JUN factors, has been demonstrated to be involved in maintaining the integrity and function of the adrenal cortex (Lehoux et al. 1998). JUN and FOS have been demonstrated to have diverse effects in cellular functions and are able to interact with different proteins and mediate a variety of transcriptional responses (Karin et al. 1997, Sarkar et al. 2000, Shea-Eaton et al. 2002, Manna et al. 2004, Manna \& Stocco 2007). Conceivably, the roles for JUN and FOS in PRKCC-responsive STAR expression and steroidogenesis are speculated to be different since they lack sequence similarity outside the DNA-binding and dimerization domains. Mice lacking JUN are embryonic lethal with embryos dying between mid- and late gestation due to several tissue defects, underscoring the importance of JUN during development (Hilberg et al. 1993, Johnson et al. 1993). Our findings show that overexpression of JUN increased basal and PMAmediated Stargene expression and that these responses were markedly affected by TAM- 67 , demonstrating that JUN plays an integral role in the transcription of the Star gene. Consequently, targeted silencing of endogenous JUN was shown to coordinately suppress PRKCCdependent STAR expression and steroid synthesis. JUN dimerizes with many bZIP members, and thus the repression of JUN in concurrence with PRKCCmediated steroidogenesis may affect relevant transcription factor(s), a possibility that requires additional investigation.

In summary, these findings provide insight into the mechanisms by which JUN regulates the PRKCC signaling pathway involved in the steroidogenic response in mouse Leydig cells. Also, our present findings support the observation that the PRKCCdependent induction of STAR expression and steroid synthesis involves signaling crosstalk with PRKACA. 
JUN binds to the JUN motif in the STAR promoter and influences PMA-induced steroid synthesis by controlling transcription of the Star gene. Whether JUN acts similarly in other steroidogenic cells in response to PRKCC remains to be elucidated.

\section{Declaration of interest}

The authors declare that there is no conflict of interest that would prejudice the impartiality of this scientific work.

\section{Funding}

This investigation was supported by NIH grant HD-17481 and with funds from the Robert A. Welch Foundation grant B1-0028.

\section{Acknowledgements}

We thank Dr G T Bowden (The University of Arizona, Tucson, AZ, USA) for providing us with the TAM-67 construct, Dr W L Miller (University of California, San Francisco, CA, USA) for the STAR Ab, and Dr C M Pfarr (Texas Tech University Health Sciences Center, Lubbock, TX, USA) for the JUN expression plasmid. MA-10 cell line was a gift from Dr M Ascoli (University of Iowa College of Medicine, Iowa City, IA, USA).

\section{References}

Abate C, Luk D \& Curran T 1991 Transcriptional regulation by Fos and Jun in vitro: interaction among multiple activator and regulatory domains. Molecular and Cellular Biology 11 3624-3632.

Abate C, Baker SJ, Lees-Miller SP, Anderson CW, Marshak DR \& Curran T 1993 Dimerization and DNA binding alter phosphorylation of Fos and Jun. PNAS 90 6766-6770.

Angel P \& Karin M 1991 The role of Jun, Fos and the AP-1 complex in cell-proliferation and transformation. Biochimica et Biophysica Acta 1072 129-157.

Arakane F, King SR, Du Y, Kallen CB, Walsh LP, Watari H, Stocco DM \& Strauss JF III 1997 Phosphorylation of steroidogenic acute regulatory protein (StAR) modulates its steroidogenic activity. Journal of Biological Chemistry 272 32656-32662.

Ascoli M 1981 Characterization of several clonal lines of cultured Leydig tumor cells: gonadotropin receptors and steroidogenic responses. Endocrinology 108 88-95.

Bakiri L, Matsuo K, Wisniewska M, Wagner EF \& Yaniv M 2002 Promoter specificity and biological activity of tethered AP-1 dimers. Molecular and Cellular Biology 22 4952-4964.

Bannister AJ, Oehler T, Wilhelm D, Angel P \& Kouzarides T 1995 Stimulation of c-Jun activity by CBP: c-Jun residues Ser63/73 are required for CBP induced stimulation in vivo and CBP binding in vitro. Oncogene 11 2509-2514.

Benbrook DM \& Jones NC 1990 Heterodimer formation between CREB and JUN proteins. Oncogene 5 295-302.

Bird IM, Mathis JM, Mason JI \& Rainey WE 1995 Ca(2+)-regulated expression of steroid hydroxylases in H295R human adrenocortical cells. Endocrinology 136 5677-5684.

Bose HS, Whittal RM, Baldwin MA \& Miller WL 1999 The active form of the steroidogenic acute regulatory protein, StAR, appears to be a molten globule. PNAS 96 7250-7255.
Caron KM, Ikeda Y, Soo SC, Stocco DM, Parker KL \& Clark BJ 1997 Characterization of the promoter region of the mouse gene encoding the steroidogenic acute regulatory protein. Molecular Endocrinology 11 138-147.

Chan YL, Lin A, McNally J, Peleg D, Meyuhas O \& Wool IG 1987 The primary structure of rat ribosomal protein L19. A determination from the sequence of nucleotides in a cDNA and from the sequence of amino acids in the protein. Journal of Biological Chemistry 262 1111-1115.

Chaudhary LR \& Stocco DM 1988 Stimulation of progesterone production by phorbol-12-myristate-13- acetate in MA-10 Leydig tumor cells. Biochimie 70 1353-1360.

Chen D, Fong HW \& Davis JS 2001 Induction of c-fos and c-jun messenger ribonucleic acid expression by prostaglandin F2 $\alpha$ is mediated by a protein kinase C-dependent extracellular signalregulated kinase mitogen-activated protein kinase pathway in bovine luteal cells. Endocrinology 142 887-895.

Chin EC \& Abayasekara DR 2004 Progesterone secretion by luteinizing human granulosa cells: a possible cAMP-dependent but PKAindependent mechanism involved in its regulation. Journal of Endocrinology 183 51-60.

Christenson LK \& Strauss JF III 2000 Steroidogenic acute regulatory protein (StAR) and the intramitochondrial translocation of cholesterol. Biochimica et Biophysica Acta 1529 175-187.

Clark BJ, Wells J, King SR \& Stocco DM 1994 The purification, cloning, and expression of a novel luteinizing hormone-induced mitochondrial protein in MA-10 mouse Leydig tumor cells. Characterization of the steroidogenic acute regulatory protein (StAR). Journal of Biological Chemistry 269 28314-28322.

Clark BJ, Combs R, Hales KH, Hales DB \& Stocco DM 1997 Inhibition of transcription affects synthesis of steroidogenic acute regulatory protein and steroidogenesis in MA-10 mouse Leydig tumor cells. Endocrinology 138 4893-4901.

Clem BF, Hudson EA \& Clark BJ 2005 Cyclic adenosine $3^{\prime}, 5^{\prime}$ monophosphate (cAMP) enhances cAMP-responsive element binding (CREB) protein phosphorylation and phospho-CREB interaction with the mouse steroidogenic acute regulatory protein gene promoter. Endocrinology 146 1348-1356.

Dyson MT, Jones JK, Kowalewski MP, Manna PR, Alonso M, Gottesman ME \& Stocco DM 2008 Mitochondrial A-kinase anchoring protein 121 binds Type II protein kinase A and enhances steroidogenic acute regulatory protein-mediated steroidogenesis in MA-10 mouse Leydig tumor cells. Biology of Reproduction 78 267-277.

Hai T \& Curran T 1991 Cross-family dimerization of transcription factors Fos/Jun and ATF/CREB alters DNA binding specificity. PNAS 88 3720-3724.

Hilberg F, Aguzzi A, Howells N \& Wagner EF 1993 c-Jun is essential for normal mouse development and hepatogenesis. Nature 365 $179-181$.

Hiroi H, Christenson LK, Chang L, Sammel MD, Berger SL \& Strauss JF III 2004 Temporal and spatial changes in transcription factor binding and histone modifications at the steroidogenic acute regulatory protein (StAR) locus associated with StAR transcription. Molecular Endocrinology 18 791-806.

Ilvesmaki V \& Voutilainen R 1991 Interaction of phorbol ester and adrenocorticotropin in the regulation of steroidogenic $\mathrm{P} 450$ genes in human fetal and adult adrenal cell cultures. Endocrinology 128 $1450-1458$.

Jo Y, King SR, Khan SA \& Stocco DM 2005 Involvement of protein kinase $\mathrm{C}$ and cyclic adenosine $3^{\prime}, 5^{\prime}$-monophosphate-dependent kinase in steroidogenic acute regulatory protein expression and steroid biosynthesis in Leydig cells. Biology of Reproduction 73 244-255.

Johnson RS, van Lingen B, Papaioannou VE \& Spiegelman BM 1993 A null mutation at the c-jun locus causes embryonic lethality and retarded cell growth in culture. Genes and Development 7 1309-1317.

Karin M, Liu Z \& Zandi E 1997 AP-1 function and regulation. Current Opinion in Cell Biology 9 240-246. 
Lehoux JG, Fleury A \& Ducharme L 1998 The acute and chronic effects of adrenocorticotropin on the levels of messenger ribonucleic acid and protein of steroidogenic enzymes in rat adrenal in vivo. Endocrinology 139 3913-3922.

LeHoux JG, Fleury A, Ducharme L \& Hales DB 2004 Phosphorylation of the hamster adrenal steroidogenic acute regulatory protein as analyzed by two-dimensional polyacrylamide gel electrophoreses. Molecular and Cellular Endocrinology 215 127-134.

Li X, Hales KH, Watanabe G, Lee RJ, Pestell RG \& Hales DB 1997 The effect of tumor necrosis factor-alpha and cAMP on induction of AP-1 activity in MA-10 tumor Leydig cells. Endocrine 6 317-324.

Lin D, Sugawara T, Strauss JF III, Clark BJ, Stocco DM, Saenger P, Rogol A \& Miller WL 1995 Role of steroidogenic acute regulatory protein in adrenal and gonadal steroidogenesis. Science $\mathbf{2 6 7}$ 1828-1831.

Manna PR \& Stocco DM 2005 Regulation of the steroidogenic acute regulatory protein expression: functional and physiological consequences. Current Drug Targets. Immune, Endocrine and Metabolic Disorders 5 93-108.

Manna PR \& Stocco DM 2007 Crosstalk of CREB and Fos/Jun on a single cis-element: transcriptional repression of the steroidogenic acute regulatory protein gene. Journal of Molecular Endocrinology 39 261-277.

Manna PR, Tena-Sempere M \& Huhtaniemi IT 1999 Molecular mechanisms of thyroid hormone-stimulated steroidogenesis in mouse Leydig tumor cells. Involvement of the steroidogenic acute regulatory (StAR) protein. Journal of Biological Chemistry $\mathbf{2 7 4}$ 5909-5918.

Manna PR, Kero J, Tena-Sempere M, Pakarinen P, Stocco DM \& Huhtaniemi IT 2001 Assessment of mechanisms of thyroid hormone action in mouse Leydig cells: regulation of the steroidogenic acute regulatory protein, steroidogenesis, and luteinizing hormone receptor function. Endocrinology 142 319-331.

Manna PR, Dyson MT, Eubank DW, Clark BJ, Lalli E, Sassone-Corsi P, Zeleznik AJ \& Stocco DM 2002 $a$ Regulation of steroidogenesis and the steroidogenic acute regulatory protein by a member of the cAMP response-element binding protein family. Molecular Endocrinology 16 184-199.

Manna PR, Huhtaniemi IT, Wang XJ, Eubank DW \& Stocco DM $2002 b$ Mechanisms of epidermal growth factor signaling: regulation of steroid biosynthesis and the steroidogenic acute regulatory protein in mouse leydig tumor cells. Biology of Reproduction 67 1393-1404.

Manna PR, Eubank DW, Lalli E, Sassone-Corsi P \& Stocco DM 2003 a Transcriptional regulation of the mouse steroidogenic acute regulatory protein gene by the cAMP response-element binding protein and steroidogenic factor 1. Journal of Molecular Endocrinology 30 381-397.

Manna PR, Wang XJ \& Stocco DM $2003 b$ Involvement of multiple transcription factors in the regulation of steroidogenic acute regulatory protein gene expression. Steroids 68 1125-1134.

Manna PR, Eubank DW \& Stocco DM 2004 Assessment of the role of activator protein-1 on transcription of the mouse steroidogenic acute regulatory protein gene. Molecular Endocrinology 18 558-573.

Manna PR, Chandrala SP, Jo Y \& Stocco DM 2006 a cAMP-Independent signaling regulates steroidogenesis in mouse Leydig cells in the absence of StAR phosphorylation. Journal of Molecular Endocrinology 37 81-95.

Manna PR, Chandrala SP, King SR, Jo Y, Counis R, Huhtaniemi IT \& Stocco DM 2006 $b$ Molecular mechanisms of insulin-like growth factor-I mediated regulation of the steroidogenic acute regulatory protein in mouse leydig cells. Molecular Endocrinology 20 362-378.
Manna PR, Jo Y \& Stocco DM 2007 Regulation of Leydig cell steroidogenesis by extracellular signal-regulated kinase 1/2: role of protein kinase A and protein kinase C signaling. Journal of Endocrinology 193 53-63.

Miller WL 2007 StAR search - what we know about how the steroidogenic acute regulatory protein mediates mitochondrial cholesterol import. Molecular Endocrinology 21 589-601.

Muller A, Lutz-Bucher B, Kienlen-Campard P, Koch B \& Loeffler JP 1998 Continuous activation of pituitary adenylate cyclase-activating polypeptide receptors elicits antipodal effects on cyclic AMP and inositol phospholipid signaling pathways in CATH.a cells: role of protein synthesis and protein kinases. Journal of Neurochemistry $\mathbf{7 0}$ $1431-4140$.

O'Shea EK, Rutkowski R \& Kim PS 1992 Mechanism of specificity in the Fos-Jun oncoprotein heterodimer. Cell 68 699-708.

Rutberg SE, Saez E, Lo S, Jang SI, Markova N, Spiegelman BM \& Yuspa SH 1997 Opposing activities of c-Fos and Fra-2 on AP-1 regulated transcriptional activity in mouse keratinocytes induced to differentiate by calcium and phorbol esters. Oncogene 15 1337-1346.

Rutberg SE, Adams TL, Olive M, Alexander N, Vinson C \& Yuspa SH 1999 CRE DNA binding proteins bind to the AP-1 target sequence and suppress AP-1 transcriptional activity in mouse keratinocytes. Oncogene 18 1569-1579.

Sarkar D, Kambe F, Hayashi Y, Ohmori S, Funahashi H \& Seo H 2000 Involvement of AP-1 and steroidogenic factor (SF)-1 in the cAMPdependent induction of human adrenocorticotropic hormone receptor (ACTHR) promoter. Endocrine Journal 47 63-75.

Shea-Eaton W, Sandhoff TW, Lopez D, Hales DB \& McLean MP 2002 Transcriptional repression of the rat steroidogenic acute regulatory (StAR) protein gene by the AP-1 family member c-Fos. Molecular and Cellular Endocrinology 188 161-170.

Silverman E, Eimerl S \& Orly J 1999 CCAAT enhancer-binding protein beta and GATA-4 binding regions within the promoter of the steroidogenic acute regulatory protein (StAR) gene are required for transcription in rat ovarian cells. Journal of Biological Chemistry 274 17987-17996.

Silverman E, Yivgi-Ohana N, Sher N, Bell M, Eimerl S \& Orly J 2006 Transcriptional activation of the steroidogenic acute regulatory protein (StAR) gene: GATA-4 and CCAAT/enhancer-binding protein beta confer synergistic responsiveness in hormone-treated rat granulosa and HEK293 cell models. Molecular and Cellular Endocrinology 252 92-101.

Stocco DM \& Clark BJ 1996 Regulation of the acute production of steroids in steroidogenic cells. Endocrine Reviews 17 221-244.

Stocco DM, Wang X, Jo Y \& Manna PR 2005 Multiple signaling pathways regulating steroidogenesis and steroidogenic acute regulatory protein expression: more complicated than we thought. Molecular Endocrinology 19 2647-2659.

Tilly JL \& Johnson AL 1989 Regulation of androstenedione production by adenosine $3^{\prime}, 5^{\prime}$-monophosphate and phorbol myristate acetate in ovarian thecal cells of the domestic hen. Endocrinology 125 1691-1699.

Vo N \& Goodman RH 2001 CREB-binding protein and p300 in transcriptional regulation. Journal of Biological Chemistry $\mathbf{2 7 6}$ $13505-13508$.

Received in final form 7 August 2008

Accepted 28 August 2008

Made available online as an Accepted Preprint 28 August 2008 